\title{
Employing Remote Sensing Tools for Assessment of Land Use/Land Cover (LULC) Changes in Eastern Province, Rwanda
}

\author{
Jean Paul Nkundabose ${ }^{1,}$, , Felix Nshimiyimana ${ }^{1}$, Gratien Twagirayezu ${ }^{2}$, Olivier Irumva ${ }^{3}$ \\ ${ }^{1}$ School of Environmental Science and Engineering, Suzhou University of Science and Technology, Suzhou, PR China \\ ${ }^{2}$ School of Environmental and Municipal Engineering, Lanzhou Jiaotong University, Lanzhou, PR China \\ ${ }^{3}$ School of Eco-Environmental Engineering, Guizhou Minzu University, Guiyang, PR China
}

Email address:

jnkundabose@gmail.com (J. P. Nkundabose)

${ }^{*}$ Corresponding author

\section{To cite this article:}

Jean Paul Nkundabose, Felix Nshimiyimana, Gratien Twagirayezu, Olivier Irumva. Employing Remote Sensing Tools for Assessment of Land Use/Land Cover (LULC) Changes in Eastern Province, Rwanda. American Journal of Remote Sensing. Vol. 9, No. 1, 2021 , pp. $23-32$. doi: 10.11648/j.ajrs.20210901.13

Received: February 27, 2021; Accepted: March 11, 2021; Published: March 22, 2021

\begin{abstract}
The present paper attempted to study land use/land cover (LULC) changes in a rural region of Eastern Province, Rwanda. The particular study area consists of part of Ngoma, Rwamagana, Kayonza, Bugesera districts of Eastern province, Rwanda, and a tiny part of Burundi. The study considered LULC changes that happened in 15 years from 2005 to 2020. By means of Remote Sensing and GIS tools, Land use/Land cover (LULC) changes were detected. Possible causes linked to historical changes were highlighted accordingly. Multi-temporal remote sensing images (Landsat imagery) were used to generate land use/land cover (LULC) maps. Two temporal satellite images were collected, preprocessed, and classified through supervised Image classification stages in ENVI 5.1. Corresponding maps were exported by ArcGIS 10.7. Seven important classes including water, bare land, wetlands, agriculture, vegetation, forest, and built-up area were classified and detected for changes using both Image change workflow and Thematic change workflow tools in ENVI 5.1. Among seven classes of land use/land cover (LULC), four experienced gains while built-up area, forest, and bare land witnessed decrease/losses over the last 15 years period (20052020). Like Forest diminished from $197.8821 \mathrm{~km}^{2}$ in 2005 to $56.9304 \mathrm{~km}^{2}$ in 2020 . Several factors including government policies and regulations, population growth, and economic development can be attributed to these changes. The present work can provide important insights on land use planning and management for the area under consideration and we believe this work to contribute to the literature on the application of ENVI and related remote sensing tools.
\end{abstract}

Keywords: Land Use/Land Cover, LULC, ENVI, Rwanda, Change Detection, Supervised Classification

\section{Introduction}

Rwanda as well as other countries on the globe are experiencing rapid, wide-ranging changes in Land use and Land cover. Land use/land cover change (LULC) is the major underlying cause of global environmental change [1]. Only a few landscapes on earth in peripheral sites and remote areas still have their natural state maintained [2]. The alarming growth rate of the global population, which in turn leads to an increase in anthropogenic activities, has greatly altered the land use and land cover (LULC) [2]. This speedy alteration in LULC leads to forest deterioration and transformation of fertile land to urban construction with a significant impact on the ecosystem [3]. LULC changes are drastically altering the earth's surface and this transformation makes land surface management one of the pressing global ecological challenges to address in the $21^{\text {st }}$ century [4]. For instance, more than 80 million ha of forest have been converted into other land uses in African countries between 1990 and 2015 [2]. Concerning natural resources management and monitoring of environmental changes, it is of great significance to understand and map LULC change. LULC studies help 
strongly in policymaking. LULC changes indicate how humans interact with the environment [5] and a plethora of factors in space and time at different magnitudes play along. These factors include socioeconomic, political, natural, cultural, and several other factors $[6,7]$. In recent decades, Rwanda has remarkably changed in terms of economy, population growth, and urbanization which in turn affect its landscape and environment in general. The part of the rural area under consideration in the eastern province of Rwanda is no exception in terms of land use/land cover (LULC) Changes. Considering various national policies like land consolidation and urban growth (Inhabitants in agglomerations) known locally as Imidugudu, Agriculture land, forest, built-up area, and several other LULC classes can be expected to change compared to colonial times. Naturally, Land is the most important resource, which is composed of soil, water, and the associated flora and fauna, thus involving the total ecosystem. As a result of economic development in terms of increase in industrialization, urbanization, and forest to agricultural land conversions, the land resources have been exploited to a greater extent leading to land degradation [8]. In the light of the above, factors attributing to Land Use Land Cover (LULC) change are directly or indirectly dependent on population growth [9]. As the population of a given area increase, the demand for land cover such as built-up area also increases, while other land cover classes such as bare land, vegetation, decreases as a result of the increased demand for the built-up area. Consequently, these changes in most cases if not continuously checked comes with certain negativities which may affect not only the environment but also its inhabitants. However, Accurate and up-to-date land cover change information is necessary for understanding and assessing the environmental consequences of such changes. The Land Use and Land Cover (LU/LC) change pattern is one of the important parameters which depict this change [8]. Land use can be defined as the use of land by humans, usually with an emphasis on the functional role of land in economic activities. In contrast, land cover can be defined as the observed biophysical features on the earth's surface [10]. Knowledge of the distribution of land use and land cover is essential for planning and management activities [8, 11]. Land use patterns reflect the character of a society's interaction with its physical environment, a fact that becomes obvious when it is possible to see different economic and social systems occupying similar environments [8, 12]. LULC changes are major issues of global environmental change. Remote Sensing has the capability of capturing such changes, extracting the change information from satellite data requires effective and automated change detection techniques $[9,13,14]$. The importance of remote sensing was emphasized as a unique view of the spatial and temporal dynamics of the processes in urban growth and land use change [15]. Satellite remote-sensing techniques have therefore been widely used in detecting and monitoring land cover changes at various scales with useful results [16-18]. In the present work, two temporal satellite images covering the area under consideration were used to detect LULC changes for the period of 15 years (2005-2020). Stepwise, images were first preprocessed using ENVI 5.1 and then processed for detecting LULC changes. Some influencing factors behind the changes were highlighted. After this introductory part, the rest of the paper is organized as follows: Section 2 presents materials and methods used in this study, Section 3 presents results and discussions, and finally, Section 4 concludes the study.

\section{Materials and Methods}

\subsection{Study Area}

Eastern Province is the largest, the most populous, and the least densely populated of Rwanda's four provinces and Kigali City. It was created in early January 2006 as part of a government decentralization program that re-organized the country's local government structures. It has seven districts: Bugesera, Gatsibo, Kayonza, Ngoma, Kirehe, Nyagatare and Rwamagana. The capital city of the Eastern Province is Rwamagana. The Eastern Province comprises the former provinces of Kibungo and Umutara, most of Kigali Rural, and part of Byumba. The present part under study is mostly covering Ngoma district and covers small parts of Bugesera, Kirehe, Kayonza, and Rwamagana districts and a tiny part of Burundi. In 2012, Ngoma district was ranked second in terms of population density (390 inhabitants $/ \mathrm{km}^{2}$ ) at the provincial level while Bugesera was fourth (282 inhabitants $/ \mathrm{km}^{2}$ ) (https://www.easternprovince.gov.rw/index.php?id=18\&L=1) A vulnerability analysis show that the Eastern Province is the most vulnerable area in Rwanda to climate change, given that it serves as the 'bread basket' of Rwanda with the largest share of arable land, therefore critical to the country's food security, with the poor particularly vulnerable to natural hazards like flooding and drought. This province is characterized by observable climate impacts, including a high frequency of rainfall deficit, late rainfall onsets, early rainfall cessations, and a significant number of dry spells. Demographic pressure associated with high demand for wood products and other human activities constitutes the main cause of reduction of the vegetation and tree cover causing soil erosion and land degradation further exacerbated during rainy seasons. Prolonged droughts are also frequent in the east and southeast and tend to be cyclical and persistent. Droughts are often responsible for famine, food shortages, reduction in plant and animal species, and displacement of people in search of food and pasture. At times this has led to conflicts over different land uses such as protected areas, for instance forcing livestock herders to move livestock into Akagera National Park during the dry season [19]. The part being analyzed for LULC changes contains important lakes like lake Mugesera, Lake Rweru, Lake sake, etc. The topography of the study area (Ngoma district) is mountainous. Using the area measurement tool in ArcMap 10.7, the rectangular-shaped study region of interest (Figure 1) covers $1360.357594 \mathrm{~km}^{2}$ area. 


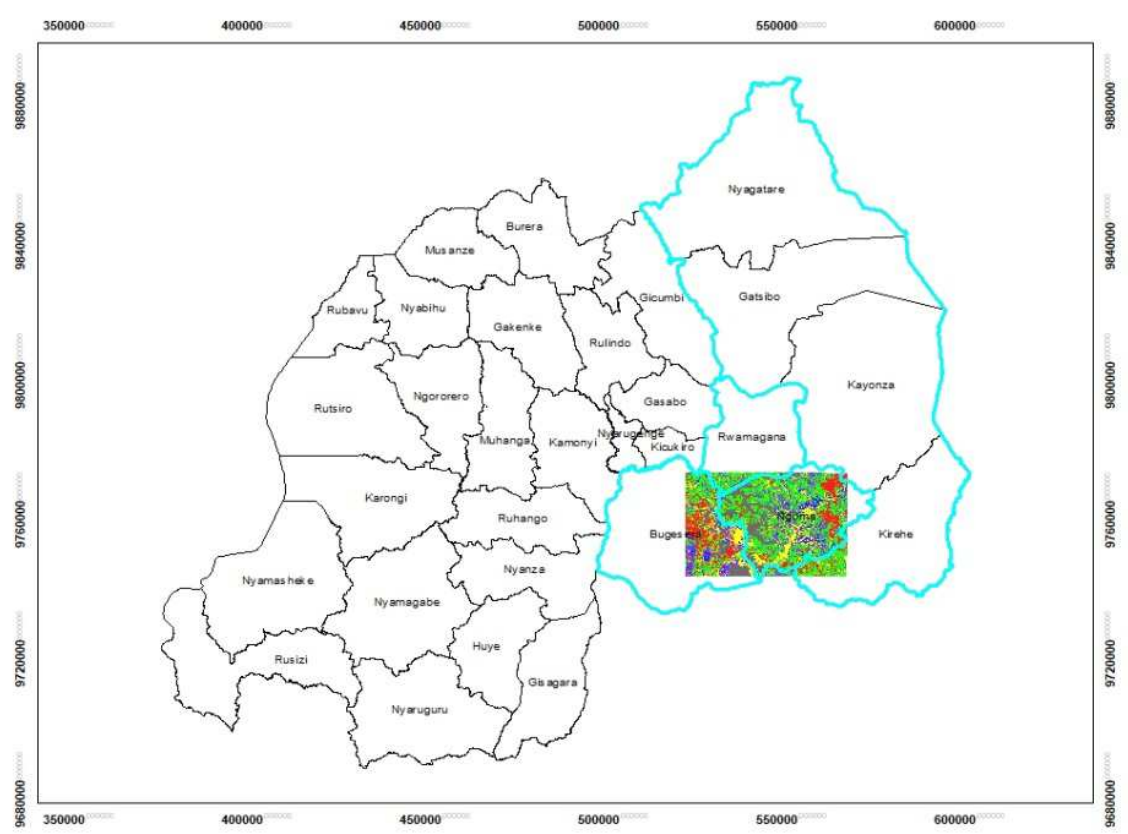

Figure 1. Study area (rectangular shaped) in Rwanda administrative map.

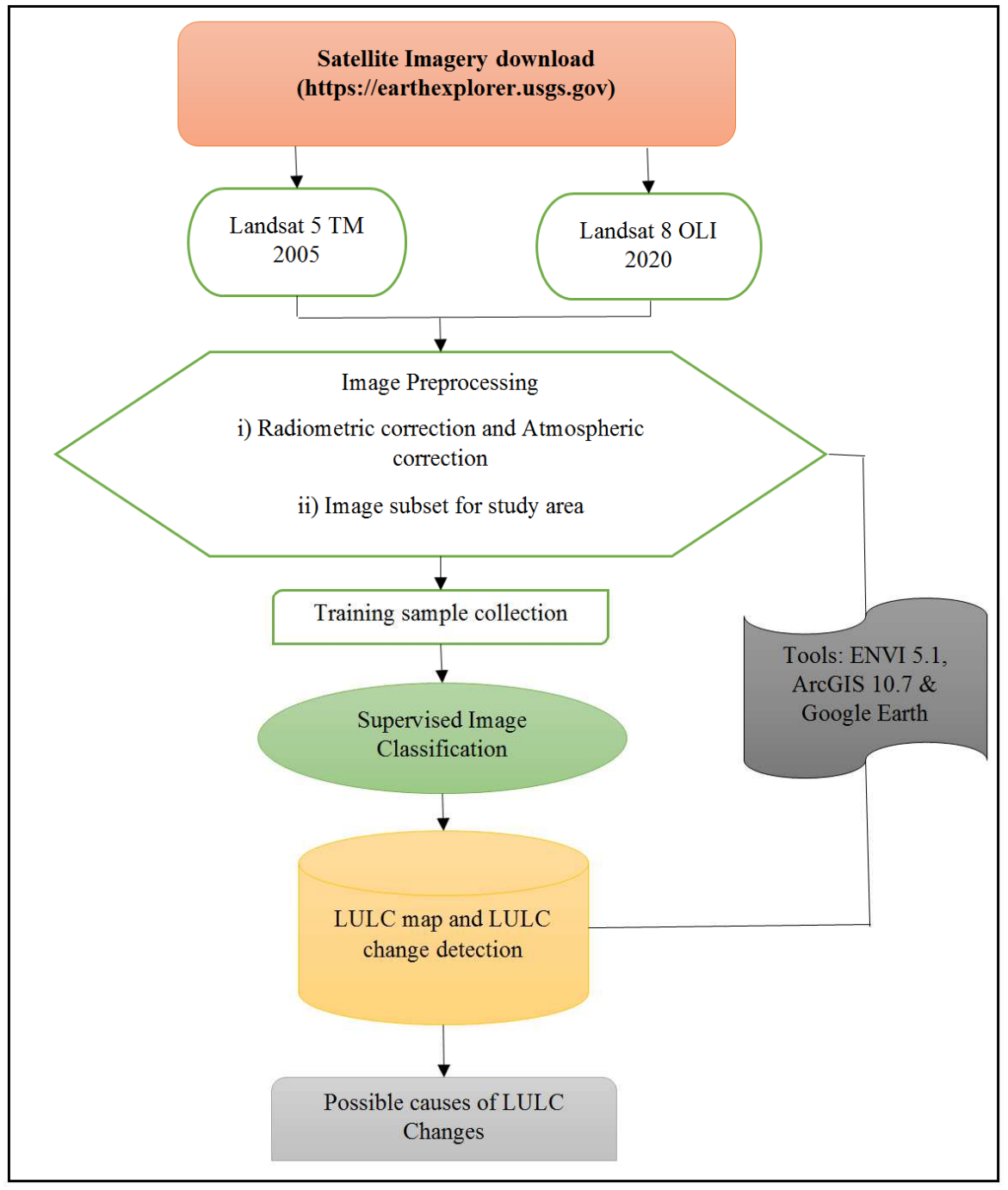

Figure 2. Stepwise methodology employed in this study. 


\subsection{Data Acquisition}

The satellite imagery used in this study is from the United States Geological Survey (USGS) earth explorer (https://earthexplorer.usgs.gov). The study area is covered by Landsat frame path row 172-62 of the Worldwide Reference System (WRS). In the present work, two scenes from Landsat 4-5 Thematic Mapper (TM) and Landsat 8 Operational Land Imager (OLI) were used to cover the study period of almost 15 years (2005-2020) (Table 1). The Landsat satellite sensor details and the wavelengths of the spectral bands are available at https://landsat.usgs.gov/whatare-band-designationslandsat- satellites. The acquisition of cloud-free satellite imagery is a major limitation in tropical regions. The acquired scenes are level-1 terrain-corrected, which are most suitable for pixel-level time-series studies. The collected images were provided in GeoTiff format and resampled to $30 \mathrm{~m}$ with the Universal Transverse Mercator (UTM)-World Geodetic System (WGS) 84 projection using the cubic convolution method. Various similar studies used imagery from this site $[9,17,18,20]$. The collected images were processed and analyzed in a stepwise process described in Figure 2.

Table 1. List of satellite imagery used in this study.

\begin{tabular}{lllll}
\hline & Acquisition date & Sensor & Path/row & Resolution (m) \\
\hline Pre-image & $10^{\text {th }}$ March, 2005 & Landsat 5 TM & $172 / 62$ & 30 \\
Post-image & $23^{\text {rd }}$ June, 2020 & Landsat 8 OLI & $172 / 62$ & 30 \\
\hline
\end{tabular}

\subsection{Image Preprocessing}

Multidata analysis can only be performed on geometrically and radiometrically corrected data. Image preprocessing should be performed to provide a data set that can be used to extract spatial information. This step helps to remove geometric and radiometric distortions and atmospheric attenuation from the satellite images. Image preprocessing was performed through a series of sequential operations such as calibration to radiance, atmospheric correction or normalization, geometric correction, and sub-setting [21]. The image processing and classification were performed using ENvironment for Visualizing Images ${ }^{\circledR}$ (ENVI) remote sensing software (Figure 2). The initial calibration was performed to convert the digital numbers (DN) of the Landsat scenes into absolute radiance units $\left(\mathrm{W} \mathrm{m}^{-2} \mathrm{sr}^{-1}\right)$ using the scene metadata. The "Fast Line-of-sight Atmospheric Analysis of Hypercubes" (FLAASH) module was used to perform the atmospheric correction [22]. The radiance image, tropical atmospheric profile, and rural aerosol model were inputs to the FLAASH. Sub-setting was performed to extract the area of interest.

\subsection{Image Classification and Training Sample Collection}

Seven broad LULC classes were categorized in the present study. The classes include Water, bare land, Wetlands, Agricultural land, built-up area (representing congested building, roads, and dispersed settlements), forest, and Vegetation (Table 2). To sample training data for image classification, Google Earth (GE) ${ }^{\mathrm{TM}}$ historical high-resolution imagery was used for land cover identification. At least 15 training samples for each class were collected for better accuracy. GE provided reference images for 2005 and the current image (2020) were used for accurate classification. The Landsat series satellites have almost similar wavelength bands and spectral characteristics that make sample collection easy. The supervised classification method was chosen to perform the image classification. This method has three stages, training, class allocation, and testing [23]. In the training stage, the region of interest (ROI) for different LULC categories was created in ENVI 5.1 using GE historical imagery.

Table 2. Land cover classification.

\begin{tabular}{|c|c|}
\hline Land cover type & Description \\
\hline Vegetation & Cultivated zones occupied with either perennial or seasonal crops, postharvest fields, pasture lands \\
\hline Forest & Areas occupied by closed forest plantation \\
\hline Built-up area & $\begin{array}{l}\text { 1) Built-up area with congested buildings, includes informal settlements } \\
\text { 2) Built-up area with ventilation space especially high standing zones, tarmac roads, scattered settlements in urban fringe zones and } \\
\text { rural areas }\end{array}$ \\
\hline Bare land & Uncovered, permissive land/soil \\
\hline Water & $\begin{array}{l}\text { Permanent natural water bodies such as lakes, rivers, fish ponds reservoirs, and man-made water bodies, the water table in irrigated } \\
\text { land }\end{array}$ \\
\hline Wetlands & Low land with permanent water with floating aquatic vegetation, seasonal flooded low land surrounded by high lands \\
\hline Agriculture & Cropland \\
\hline
\end{tabular}

\section{Results and Discussions}

\subsection{LULC Classification and Mapping}

ENVI supervised image classification provided the final LULC maps for the corresponding years as shown in Figures
3 \& 4. By visual interpretation, changes can be seen in agriculture, bare land, and Built-up area. Agriculture land increased from 2005 to 2020 while bare land is decreasing. Built-up area in the before image (pre-image of 2005) consisted of scattered settlements while in 2020 built-up area can be associated with congested or dense buildings or other built-up structures 


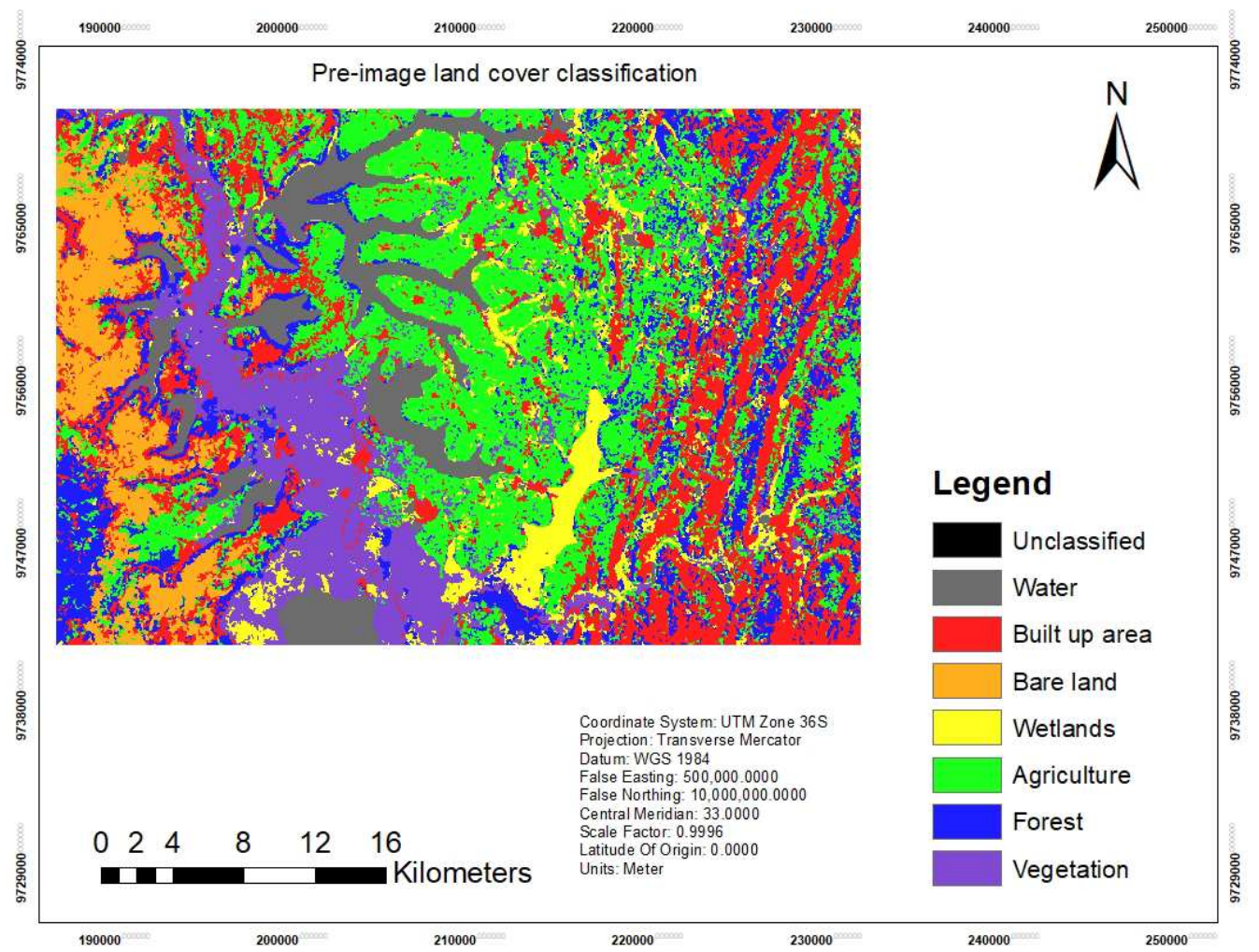

Figure 3. LULC map for 2005.

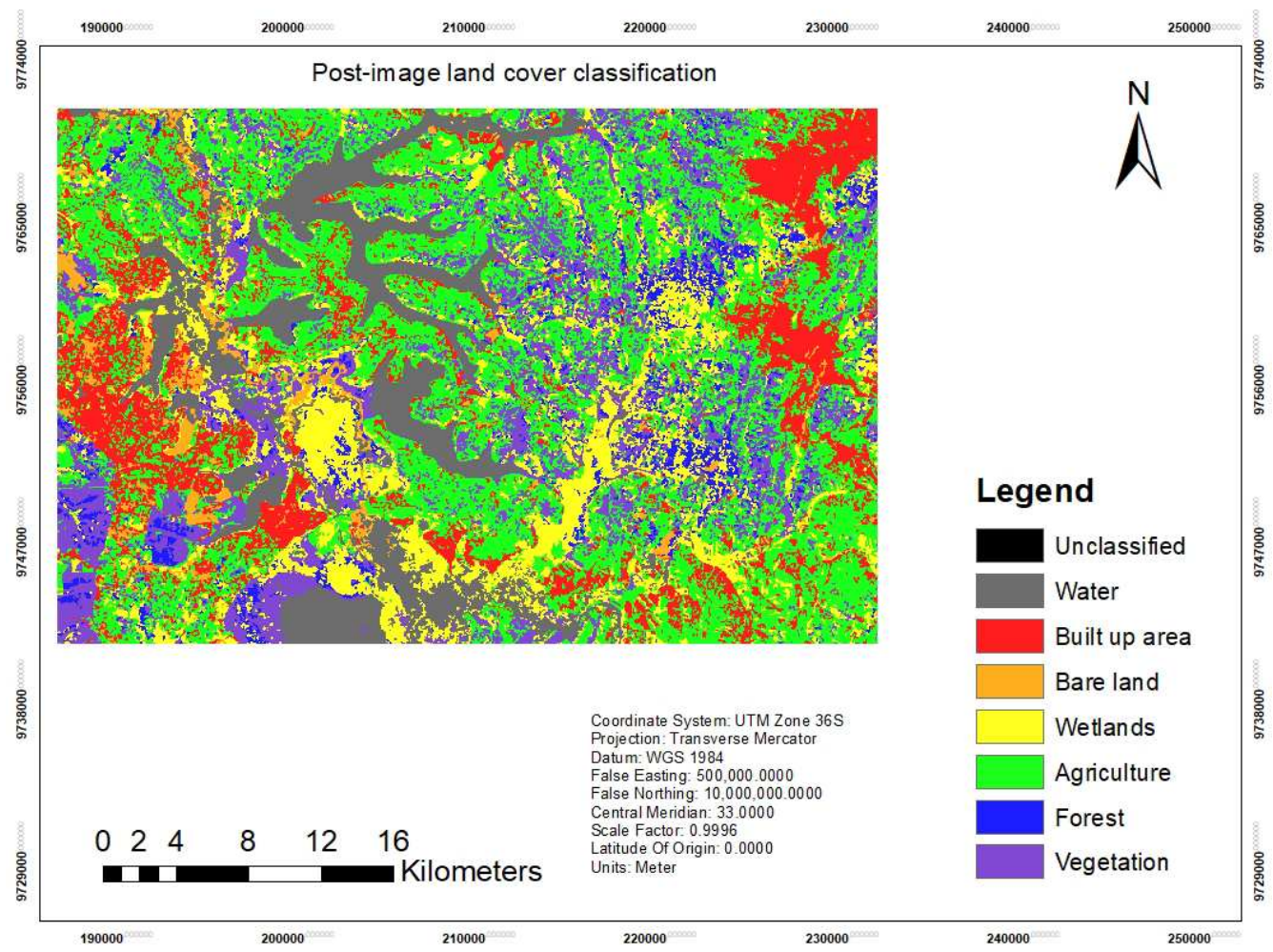

Figure 4. LULC map for 2020.

\subsection{LULC Change Detection (2005-2020)}

In this part, the study used both image change workflow and thematic change workflow to detect LULC changes that happened for 15 years period. Image change workflow 
process resulted in Figures 5 \& 6. Looking at figure 5, areas that decreased in the data value of the selected band appear as red while areas that increased appear as blue. In contrast, Thematic change detection takes two classification images (before and after images) of the same scene at different times and identifies differences between them. Figure 7 illustrates the thematic LULC changes that happened at the LULC class scale. Table 3 and Figure 8 illustrate the total change scenario (2005-2020) with conversion statistics of each class.

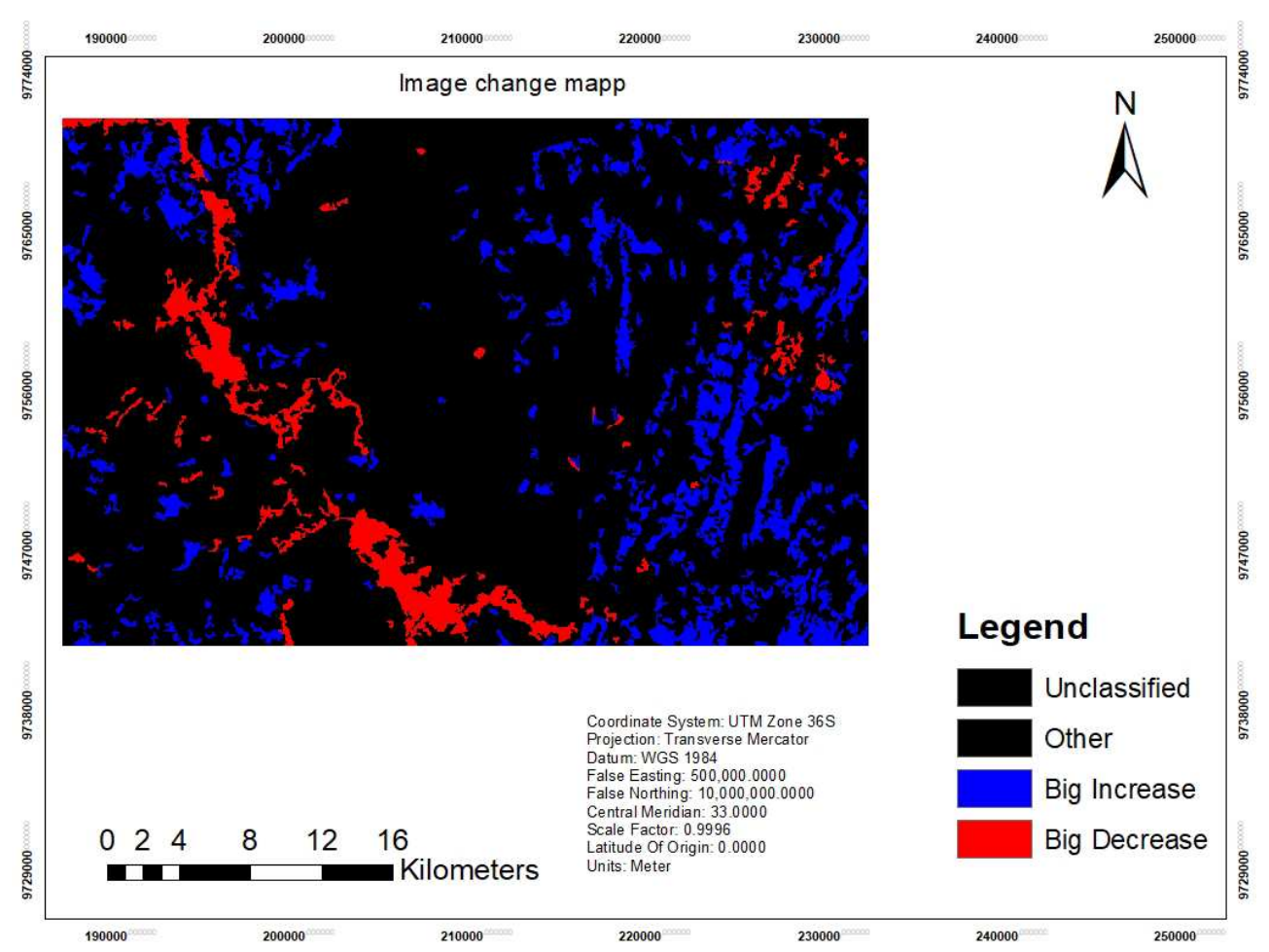

Figure 5. Image change map (2005-2020).

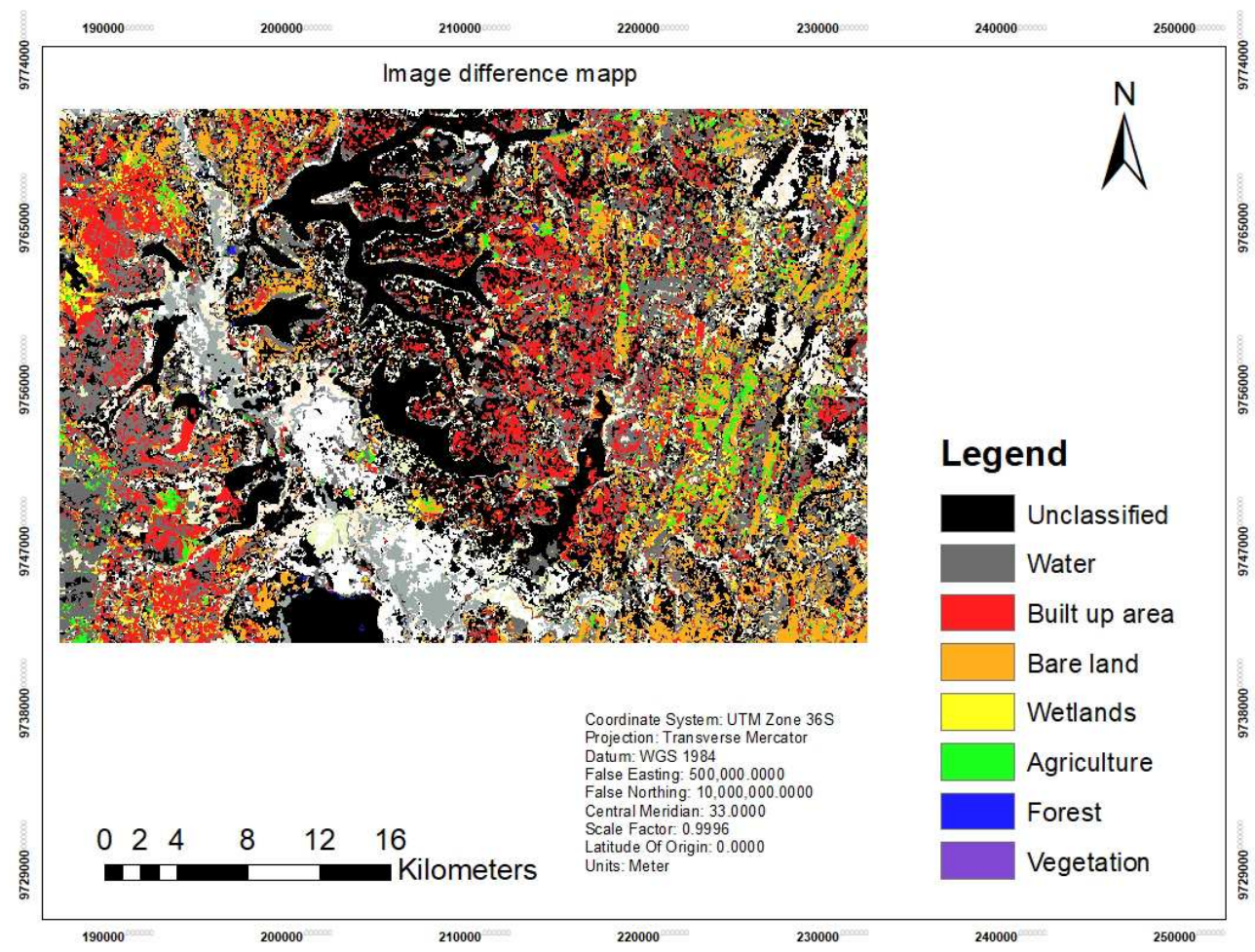

Figure 6. Image difference map (2005-2020). 


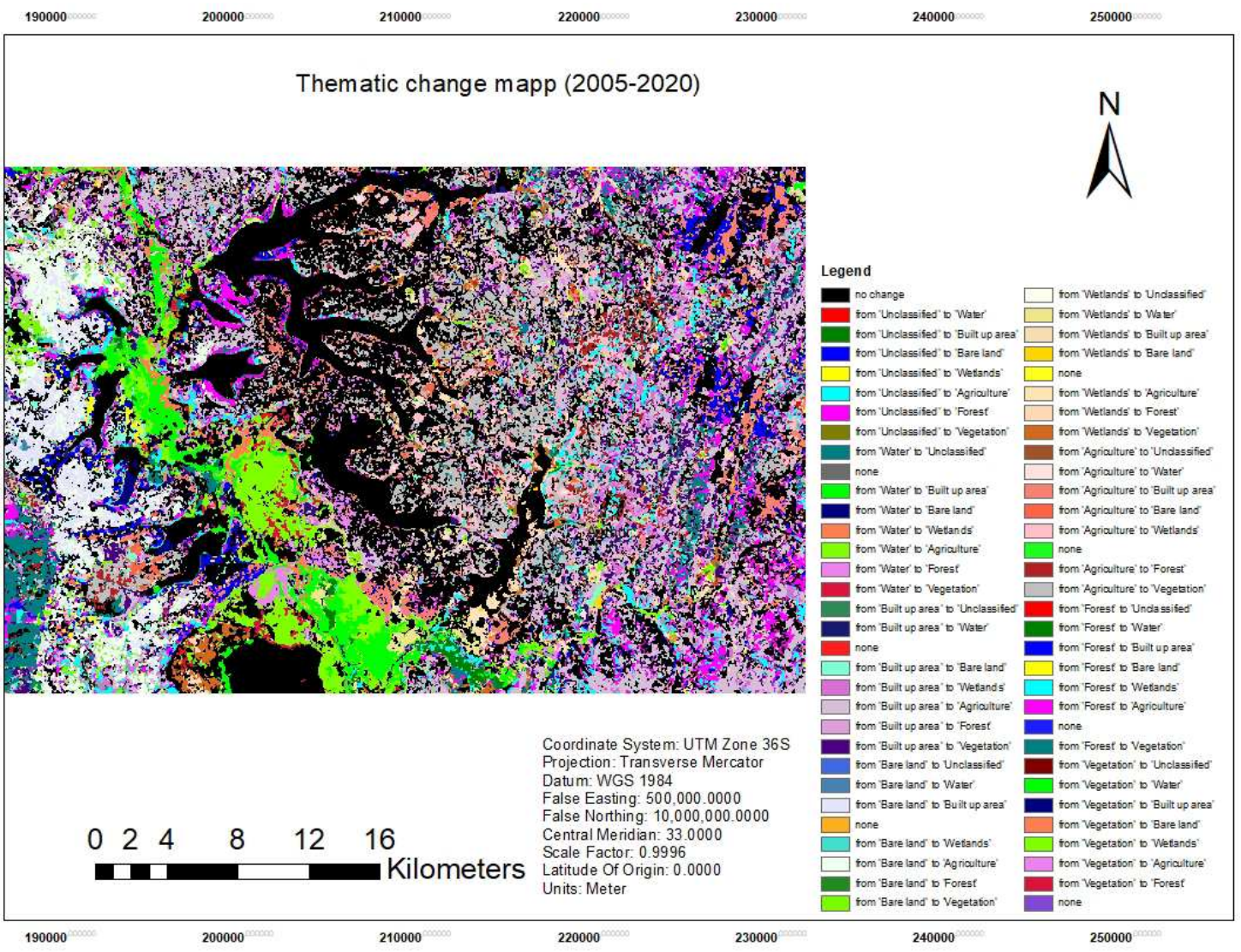

Figure 7. Thematic Changes happened (2005-2020).

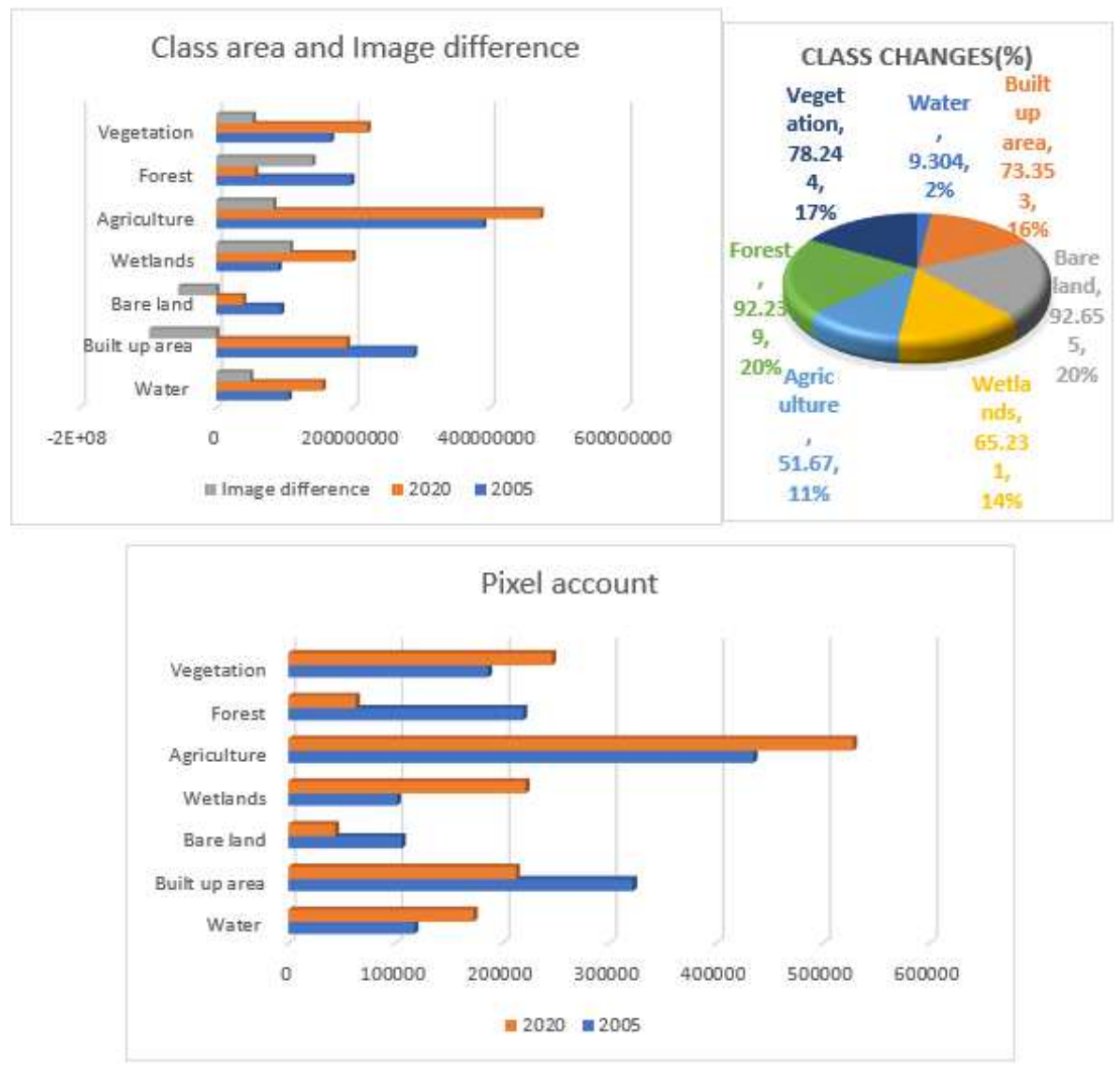

Figure 8. Areal changes/ Gain and losses; class changes by percentage and changes by pixel account. 
Table 3. Areal class changes statistics (2005-2020).

\begin{tabular}{|c|c|c|c|c|c|c|c|c|c|}
\hline \multicolumn{10}{|c|}{ Initial State (2005) Area in $\mathrm{Km}^{2}$} \\
\hline & & Water & Built-up area & Bare land & Wetlands & Agriculture & Forest & Vegetation & Row Total \\
\hline \multirow{10}{*}{$\begin{array}{l}\text { Final } \\
\text { State } \\
(2020)\end{array}$} & Water & 96.3693 & 4.563 & 0.3825 & 8.226 & 2.673 & 7.7724 & 36.0603 & 156.0465 \\
\hline & Built up area & 0.855 & 77.3082 & 31.077 & 4.7358 & 42.3774 & 30.177 & 4.9842 & 191.5146 \\
\hline & Bare land & 2.3238 & 11.16 & 7.0119 & 1.2186 & 4.6863 & 4.6278 & 8.3745 & 39.4029 \\
\hline & Wetlands & 1.6668 & 26.6742 & 3.7035 & 31.833 & 47.5893 & 37.0332 & 51.2406 & 199.7406 \\
\hline & Agriculture & 2.7486 & 130.6908 & 43.8525 & 22.0122 & 189.1935 & 63 & 23.8374 & 475.335 \\
\hline & Forest & 0.4842 & 7.2873 & 1.0233 & 6.4539 & 19.0305 & 15.3567 & 7.2945 & 56.9304 \\
\hline & Vegetation & 1.8072 & 32.4324 & 8.4096 & 17.0757 & 85.914 & 39.915 & 36.4311 & 221.985 \\
\hline & Class Total & 106.2549 & 290.1159 & 95.4603 & 91.5552 & 391.464 & 197.8821 & 168.2226 & \\
\hline & Class Changes & 9.8856 & 212.8077 & 88.4484 & 59.7222 & 202.2705 & 182.5254 & 131.7915 & \\
\hline & Image Difference & 49.7916 & -98.6013 & -56.0574 & 108.1854 & 83.871 & 140.9517 & 53.7624 & \\
\hline
\end{tabular}

\subsubsection{Changes in Built-up Area Class}

The built-up area which comprises the low, medium, and high densities road network and other manmade structures has witnessed a significant decrease based on the analysis carried out (Figure 8 and Table 3 ). This class declined from $290.1159 \mathrm{~km}^{2}$ in 2005 to $191.5146 \mathrm{~km}^{2}$ in 2020. Large areas of this particular class amounting to $31.077 \mathrm{~km}^{2}, 42.3774 \mathrm{~km}^{2}$, and $30.177 \mathrm{~km}^{2}$ were converted into bare land, agriculture, and forest, respectively (Table 3). Normally, the change in the built-up area can be associated either with construction activities, demolition activities, and a change in population density. According to the World Bank, population density in Rwanda has kept growing from the year 1961 to the year 2018 with an annual growth rate of $2.55 \%$ [26]. One square kilometer of land area in Rwanda was inhabited by 359 people in 2005 and 499 people in 2018 (recent year). The higher the population density means the higher demand in shelter and food. With government housing policy and other development policies, Rwanda's housing structure has drastically changed from unplanned and unorganized settlements to decent and sustainable housing [27]. After the 1994 genocide against Tutsi, grouped settlements (imidugudu) were chosen to improve rural settlements in Rwanda. Hence, the decrease in Built-up area here can be linked to change in the housing system. In the past years, there were scattered buildings compared to congested buildings that are presently available in Rwanda as a whole as well as the area of consideration.

\subsubsection{Changes in Agriculture Class}

Currently, maize, rice, wheat, Irish potato, beans, tea, flowers, coffee, pyrethrum, sugarcane, and cassava are the priority crops grown in Rwanda, aligning within the policy of the Crop Intensification Programme (CIP) initiated by the government in 2007 [24]. More than $60 \%$ of Rwandan soil is suitable for agriculture as the soils are fertile. Rwanda agrisector is noticeably being boosted by the government. The present work has shown a drastic increase in the available agricultural land within the study area (Figure 8 and Table 3). This class enlarged from $391.464 \mathrm{~km}^{2}$ in 2005 to 475.335 $\mathrm{km}^{2}$ in 2020. Agricultural land amounting to $130.6908 \mathrm{~km}^{2}$, $43.8525 \mathrm{~km}^{2}$, and $63 \mathrm{~km}^{2}$ was converted into built-up area, bare land, and forest, respectively (Table 3 ). The increase in agriculture can be attributed to the high demand for food and economic development where people are now using improved techniques in agriculture and grow crops on a large scale. As per Food and Agriculture Organization of the United Nations (FAO), $70 \%$ of the Rwandan population are engaged in agriculture as the main economic activity [25] and this implies the high need of land although the land resource is very scarce in Rwanda. The high population growth rate of Rwanda implies high demand of food as well as agricultural land. The driver variable of this increase in agriculture class for the considered area in this study can, in the same way, be linked to the high demand of food due to the upsurge in population growth and agriculture intensification. The increase in agriculture ensures food security.

\subsubsection{Changes in Wetlands Class}

By definition, wetland refers to "an area that is periodically or continuously inundated by shallow water or has saturated soils, and where plant growth and other biological activities are adapted to the wet conditions" [28]. The wetlands which are made up of the river, waterlogged areas, and small ponds have witnessed an increase. This class enlarged from $91.5552 \mathrm{~km}^{2}$ in 2005 to $199.7406 \mathrm{~km}^{2}$ in 2020. Normally, wetlands are dynamic and develop through time in response to changing external conditions either tectonic, geological, climatic, or sea level. Wetlands area amounting to $26.6742 \mathrm{~km}^{2}, 47.5893 \mathrm{~km}^{2}, 37.0332 \mathrm{~km}^{2}$, and $51.2406 \mathrm{~km}^{2}$ was converted into built-up area, agriculture, forest, and vegetation, respectively (Table 3). The change in wetlands area can be associated with geomorphological processes and climatic settings [28].

\subsubsection{Changes in Vegetation Class}

Vegetation has significantly increased over the last 15 years. This class enlarged from $168.2226 \mathrm{~km}^{2}$ in 2005 to $221.985 \mathrm{~km}^{2}$ in 2020. This change can be related to government policies such as those of soil erosion and landslides prevention. The government put the effort into tree planting over the years. This is not just for erosion prevention but also it helps to emit low carbon emissions. In addition, vegetation area amounting to $85.914 \mathrm{~km}^{2}, 39.915 \mathrm{~km}^{2}$, and $32.4324 \mathrm{~km}^{2}$ was transformed into agriculture, forest, and built-up area, respectively (Table 3 ). Vegetation increase is a good sign for sustainable biodiversity conservation. 


\subsubsection{Changes in Forest and Bare Land Classes}

These two classes have witnessed a decrease in the considered period. Forest diminished from $197.8821 \mathrm{~km}^{2}$ in 2005 to $56.9304 \mathrm{~km}^{2}$ in 2020 whereas bare land declined from $95.4603 \mathrm{~km}^{2}$ in 2005 to $39.4029 \mathrm{~km}^{2}$. Forest area amounting to $19.0305 \mathrm{~km}^{2}$ and $7.2945 \mathrm{~km}^{2}$ was converted into agriculture and vegetation, respectively. Besides, bare land amounting to $11.16 \mathrm{~km}^{2}$ and $8.3745 \mathrm{~km}^{2}$ was converted into built-up area and vegetation, respectively (Table 3 ). The change in forest and bare land can be closely linked to the increase in agriculture. Some forest and bare land areas have turned out to be agricultural land to hamper food insecurity. Built-up areas can also contribute to the decrease of the forest with overexploitation of it to find some wood construction materials in case no clear policies and regulations. Bare land can also be diminished by the acquisition of land for construction. The loss in the forest can negatively affect biodiversity and atmospheric conditions.

\subsubsection{Water}

This natural class has also witnessed a slight increase. Water augmented from $106.2549 \mathrm{~km}^{2}$ in 2005 to 156.0465 $\mathrm{km}^{2}$ in 2020. Compared to other classes, this class did not change to a high extent. Water bodies in the considered region are mainly various small lakes. However, water class area amounting to $36.0603 \mathrm{~km}^{2}, 7.7724 \mathrm{~km}^{2}$, and $8.226 \mathrm{~km}^{2}$ was converted into vegetation, forest, and wetlands, respectively (Table 3). Generally, water increase or decrease can be linked to climate change either prolonged heavy rainfall, ice melting or prolong droughts/global warming. It can also increase due to water resources development projects like the construction of dams or reservoirs.

\section{Conclusions}

Employing Remote Sensing and GIS tools in analyzing the LULC trend over the years was found helpful in the present study. All LULC classes except forest, built-up area, and bare land have increased over the last 15 years as depicted in Figure 8 and Table 3. Specifically, wetlands, agriculture, and vegetation classes witnessed a big increase. Agricultural land expanded from $391.464 \mathrm{~km}^{2}$ in 2005 to $475.335 \mathrm{~km}^{2}$ in 2020 while vegetation augmented from $168.2226 \mathrm{~km}^{2}$ in 2005 to $221.985 \mathrm{~km}^{2}$ in 2020 . Forest was highly diminished over the years (from $197.8821 \mathrm{~km}^{2}$ in 2005 to $56.9304 \mathrm{~km}^{2}$ in 2020). Surprisingly, the built-up area witnessed a decrease. We suggested some possible causes or implications that are linked to some LULC changes that happened in the considered period. The data presented in this paper are solely depending on the user experience. Future researches can consider accuracy assessment for better and very reliable results. Although image preprocessing was conducted in this study, the quality of satellite images is still questionable in terms of being cloudfree and this lowers the accuracy of the results. Based on the literature, supervised image classification employed in this study was used by various researchers and found to give better results and high accuracy. This study is very important in the application domain of GIS and remote sensing. To successfully identify implications or drivers of LULC changes, future researches can also include a socio-ecological survey, various RS images of different years, improved methods of classification precision of RS images.

\section{Acknowledgements}

This study is part of the final term paper for the Master's course (3012) of Environmental spatial modeling with GIS and Remote Sensing at Suzhou University of Science and Technology, School of Environmental Science and Engineering.

\section{References}

[1] Sala O. E et al. (2000). Global biodiversity scenarios for the year 2100. Science, Vol. 287, pp. 1770-1774., DOI: 10.1126/science.287.5459.1770.

[2] Alawamy, J. S., Balasundram, S. K., Hanif, A. H. M., \& Sung, C. T. B. (2020). Detecting and analyzing land use and land cover changes in the Region of Al-Jabal Al-Akhdar, Libya using time-series landsat data from 1985 to 2017. Sustainability

https://doi.org/10.3390/su12114490.

(Switzerland).

[3] Al-sharif, A. A. A., \& Pradhan, B. (2014). Monitoring and predicting land use change in Tripoli Metropolitan City using an integrated Markov chain and cellular automata models in GIS. Arabian Journal of Geosciences. https://doi.org/10.1007/s12517-013-1119-7.

[4] Ayele, G. T., Tebeje, A. K., Demissie, S. S., Belete, M. A., Jemberrie, M. A., Teshome, W. M., Mengistu, D. T., \& Teshale, E. Z. (2018). Time series land cover mapping and change detection analysis using geographic information system and remote sensing, Northern Ethiopia. Air, Soil and Water Research. https://doi.org/10.1177/1178622117751603.

[5] Sharma, R., Nguyen, T. T., \& Grote, U. (2018). Changing consumption patterns-drivers and the environmental impact. In Sustainability (Switzerland). https://doi.org/10.3390/su10114190.

[6] Omar, P. J., Gupta, N., Tripathi, R. P., Shekhar, S., \&. S. (2017). A Study of Change in Agricultural and Forest Land in Gwalior City Using Satellite Imagery. SAMRIDDHI: A Journal of Physical Sciences, Engineering and Technology. https://doi.org/10.18090/samriddhi.v9i02.10870.

[7] DeFries, R., Hansen, A., Turner, B. L., Reid, R., \& Liu, J. (2007). Land use change around protected areas: Management to balance human needs and ecological function. In Ecological Applications. https://doi.org/10.1890/05-1111.

[8] Ganasri B. P and Dwarakish G. S. (2015). Study of Land use/land Cover Dynamics through Classification Algorithms for Harangi Catchment Area, Karnataka State, INDIA. Aquatic Procedia, Vol. 4, pp. 1413-1420, DOI: 10.1016/j.aqpro.2015.02.183.

[9] Kafi K. M., Shafri H. Z. M and Shariff A. B. M. (2014). An analysis of LULC change detection using remotely sensed data: A Case study of Bauchi City. IOP Conference Series: Earth and Environmental Science, Vol. 20, DOI: 10.1088/1755-1315/20/1/012056. 
[10] Lillesand T. M., Kiefer R. W and Chipman J. W. (2015). Remote sensing and image interpretation, $7^{\text {th }}$ ed, Wiley, 2015, pp. $1-770$.

[11] Lin Y. P., Verburg P. H., Chang C. R., Chen H. Y., and Chen M. H. (2009). Developing and comparing optimal and empirical land-use models for the development of an urbanized watershed forest in Taiwan. Landscape and Urban Planning, Vol. 92, pp. 242-254, DOI: 10.1016/j.landurbplan.2009.05.003.

[12] Su C. et al. (2011). Land use change and anthropogenic driving forces: A case study in Yanhe River Basin. Chinese Geographical Science, Vol. 21, No. 5, pp. 587-599, DOI: 10.1007/s11769-011-0495-8.

[13] Roy D. P., Lewis P. E., and Justice C. O. (2002). Burned area mapping using multi-temporal moderate spatial resolution data-a bi-directional reflectance model-based expectation approach. Remote Sensing of Environment, Vol. 83, pp. 263286, DOI: 10.1016/S0034-4257(02)00077-9.

[14] Dewan A. M. and Yamaguchi Y. (2009) "Land use and land cover change in Greater Dhaka, Bangladesh: Using remote sensing to promote sustainable urbanization", Applied Geography, Vol. 29, pp. 390-401, DOI: 10.1016/j.apgeog.2008.12.005.

[15] Barnsley M. J., Longley P. A., Batty M., and Howes D. (2010). Predicting Temporal Patterns in Urban Development from Remote Imagery: in Remote Sensing and Urban Analysis, $1^{\text {st }}$ ed, CRC Press, 2010, pp. 1-20.

[16] Gilmore M. S. et al. (2008). Integrating multi-temporal spectral and structural information to map wetland vegetation in a lower Connecticut River tidal marsh. Remote Sensing of Environment, Vol. 112, pp. 4048- 4060, DOI: 10.1016/j.rse.2008.05.020.

[17] Duraisamy V., Bendapudi R., and Jadhav A. (2018). Identifying hotspots in land use land cover change and the drivers in a semi-arid region of India. Environ. Monit. Assess., Vol. 190, No. 9, pp. 1-21, DOI: 10.1007/s10661-018-6919-5.

[18] Roy A. and Inamdar A. B. (2019). Multi-temporal Land Use Land Cover (LULC) change analysis of a dry semi-arid river basin in western India following a robust multi-sensor satellite image calibration strategy. Heliyon, Vol. 5, No. e01478, DOI: 10.1016/j.heliyon.2019.e01478.

[19] REMA. (2019). Transforming Eastern Province of Rwanda's capacity to adapt to climate change through forests and landscape restoration. Rwanda Environment Management Authority, pp. 1-12.
[20] Liping C., Yujun S., and Saeed S. (2018). Monitoring and predicting land use and land cover changes using remote sensing and GIS techniques-A case study of a hilly area, Jiangle, China. PLoS One, Vol. 13, No. 5, pp. 1-23, DOI: 10.1371/journal.pone.0200493.

[21] Coppin P., Jonckheere I., Nackaerts K., Muys B., and Lambin E. (2004). Digital change detection methods in ecosystem monitoring: A review. International Journal of Remote Sensing, Vol. 29, No. 5, pp. 1565-1596, DOI: $10.1080 / 0143116031000101675$.

[22] Cooley T. et al. (2002). FLAASH, a MODTRAN4-based atmospheric correction algorithm, its applications and validation. International Geoscience and Remote Sensing Symposium (IGARSS), pp. 1414-1418, DOI: 10.1109/igarss.2002.1026134.

[23] Mathur A. and Foody G. M. (2008). Crop classification by support vector machine with intelligently selected training data for an operational application. International Journal of Remote Sensing, Vol. 29, No. 8, pp. 2227-2240, DOI: $10.1080 / 01431160701395203$.

[24] Nambajimana J. D et al. (2020). Land use change impacts on water erosion in Rwanda. Sustainability, Vol. 12, No. 50, pp. 1-23, DOI: $10.3390 /$ SU12010050.

[25] Food and Agriculture Organization of the United Nations (FAO). FAO in Rwanda: Rwanda at a glance. Accessed on 11/02/2021 at http://www.fao.org/rwanda/our-office-inrwanda/rwanda-at-a-glance/en/.

[26] The World Bank. Population density (people per sq.km of land area)-Rwanda. Accessed on 11/02/2021 at https://data.worldbank.org/indicator/EN.POP.DNST?locations $=$ RW\&most_recent_year_desc $=$ false.

[27] Rwanda Ministry of Infrastructure. (2015). National Housing Policy. Accessed on 11/02/2021 at https://www.rha.gov.rw/fileadmin/user_upload/documents/Ge neral_documents/Housing_regulations_and_standards/Policies /National_Housing_Policy.pdf.

[28] Tooth S. et al. (2015). 10 reasons why the geomorphology of wetlands is important", Climate Change Consortium of Wales (C3W), Accessed on 11/02/2021 at $\mathrm{http}: / /$ wetlandsindrylands.net/wp-content/uploads/2015/10/10Reasons-Geomorphology-of-Wetlands-NEAR-FINAL-FULLCOLOUR.pdf. 